\title{
The origin of the dual fluorescence of protonated ellipticine in water
}

\author{
Zsombor Miskolczy, ${ }^{\mathrm{a}}{ }^{\text {László Biczók, }}{ }^{\mathrm{a}^{*}}{ }^{\text {István Jablonkai }}{ }^{\mathrm{b}}$ \\ ${ }^{a}$ Institute of Materials and Environmental Chemistry, Research Centre for Natural \\ Sciences, Hungarian Academy of Sciences, P.O. Box 286, 1519 Budapest, Hungary \\ ${ }^{b}$ Institute of Organic Chemistry, Research Centre for Natural Sciences, Hungarian \\ Academy of Sciences, P.O. Box 286, 1519 Budapest, Hungary
}

\footnotetext{
*Corresponding author. E-mail: biczok.laszlo@ttk.mta.hu
} 


\begin{abstract}
Absorption and fluorescence spectroscopic measurements, as well as isothermal calorimetric titrations showed that the biexponential decay kinetics of protonated ellipticine $\left(\mathrm{EH}^{+}\right)$ fluorescence in water originates from dimerization. Due to the high equilibrium constant for the association of two $\mathrm{EH}^{+}$and the intense fluorescence of the dimer, deviation from the exponential emission intensity decay commences below micromolar concentrations. Dimerization must be taken into account when $\mathrm{EH}^{+}$concentration is determined by spectrophotometry, and when $\mathrm{EH}^{+}$ binding to substrates are studied. The molar absorption coefficients of the monomer and dimer were determined.
\end{abstract}

Key words: association, alkaloids, calorimetry, fluorescence, thermodynamics 


\section{Introduction}

Ellipticine (E), a natural pyridocarbazole type alkaloid, has attracted considerable attention due to its anticancer [1] and antimalarial [2] activity. To gain a deeper understanding of the factors controlling the excited state relaxation processes, the fluorescent behavior of $\mathrm{E}$ was examined in organic solvents of a wide range of polarities and hydrogen bonding capabilities [3]. Selfassembling peptides was found to stabilize this alkaloid in water [4,5]. The native fluorescence of $\mathrm{E}$ and its protonated form $\left(\mathrm{EH}^{+}\right)$was exploited to monitor their uptake and intracellular distribution [6,7]. The markedly different fluorescence features of $\mathrm{E}$ and $\mathrm{EH}^{+}$enabled the detection of the extent of protonation in different intracellular compartments [7] and the proton movement in mitochondria [8]. Time-resolved fluorescence measurements showed the substantial variation of the fluorescence lifetime upon binding to various subcellular constituents [9]. Biexponential decay of $\mathrm{EH}^{+}$fluorescence was always observed in water, but the individual emitting components could not be identified, and the variation of the average lifetime was only discussed, which has no physical meaning [10,11].

The main goal of the present studies was to unravel why $\mathrm{EH}^{+}$fluorescence does not follow exponential decay kinetics in aqueous solution. This knowledge is inevitably necessary for the correct interpretation of the time-resolved spectroscopic data in the presence of all types of additives, and contributes to the deeper understanding of the photophysical behavior in various microenvironments. We intend to reveal whether interaction between two $\mathrm{EH}^{+}$molecules occurs. Dimerization may significantly influence the biological activity, binding characteristics, and photoinitiated processes of $\mathrm{EH}^{+}$. Therefore, it is of fundamental importance to examine the interaction between these alkaloid cations. Self-association can cause deviation from the

Lambert-Beer law leading to systematic error in the spectrophotometrically measured $\mathrm{EH}^{+}$ 
concentrations, which propagates to the equilibrium constants derived for $\mathrm{EH}^{+}$binding to various substrates. To the best of our knowledge, the dimerization has never been taken into account in the determination of the molar absorption coefficient and binding constants of $\mathrm{EH}^{+}$. The formula of the investigated compound is presented in Scheme 1.

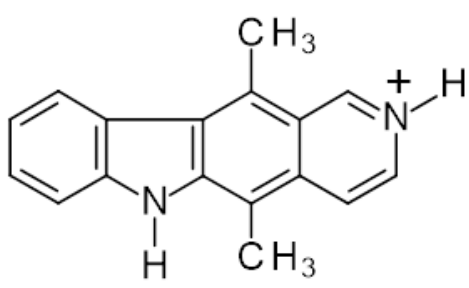

Scheme 1 Chemical structure of protonated ellipticine $\left(\mathrm{EH}^{+}\right)$

\section{Experimental Section}

Ellipticine ( $\geq 99 \%$ by HPLC, Fluka) was used as received. Slightly more than stoichiometric amount of concentrated $\mathrm{HCl}$ aqueous solution was added to ellipticine in ethanol. The solvent and the excess of $\mathrm{HCl}$ were evaporated under a flow of nitrogen. $\mathrm{EH}^{+} \mathrm{Cl}^{-}$salt prepared thereby was dissolved in $10^{-4} \mathrm{M} \mathrm{HCl}$ aqueous solution. The UV-visible absorption spectra were measured on an Agilent Technologies Cary60 spectrophotometer. Corrected fluorescence spectra were recorded on a Jobin-Yvon Fluoromax-4 photon counting spectrofluorometer. Fluorescence decays were collected with time-correlated single photon counting technique using the previously described instrument [12]. The results of spectrophotometric and fluorescence titrations were analyzed with homemade programs written in MATLAB 7.9. Isothermal titration calorimetry was carried out with a VP-ITC (GE Healthcare) instrument at $298 \mathrm{~K}$ using degassed solutions and stirring at $300 \mathrm{rpm}$. The results were analyzed using Microcal ORIGIN software. The first data point was always removed. The titrations were repeated at least three times. 


\section{Results and Discussion}

\subsection{Spectrophotometric studies}

A $\mathrm{pK}_{\mathrm{a}}$ value of $7.4 \pm 0.1$ has been reported for $\mathrm{EH}^{+}$[13]. To ensure complete protonation, experiments were performed at $\mathrm{pH}$ 4. Figure 1 demonstrates that the absorption spectrum strongly depends on the total $\mathrm{EH}^{+}$concentration $\left(\left[\mathrm{EH}^{+}\right]_{\mathrm{T}}\right)$. The apparent molar absorption coefficient $(\varepsilon)$ was calculated on the basis of the Lambert-Beer equation. The intense band with a
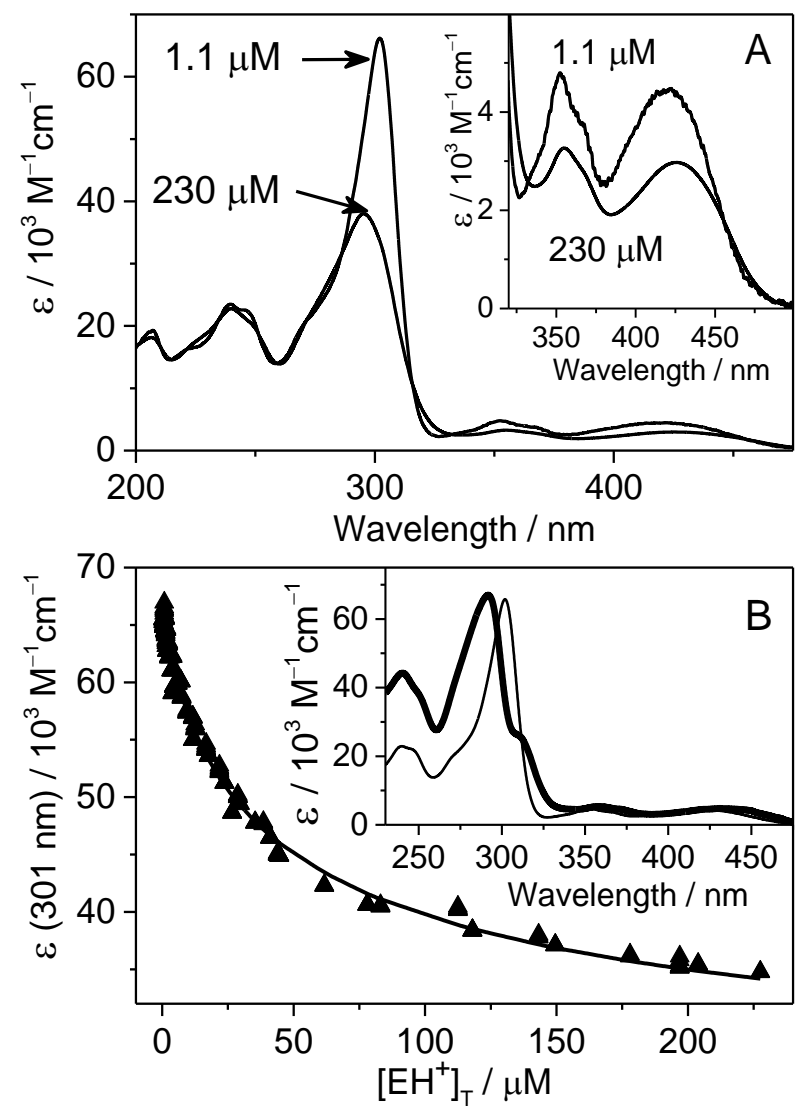

Figure 1. (A) Absorption spectra of 1.1 and $230 \mu \mathrm{M} \mathrm{EH}^{+}$in $10^{-4} \mathrm{M} \mathrm{HCl}$ aqueous solution. Inset displays the zoomed view of the long-wavelength range. (B) Variation of the apparent molar absorption coefficient at $301 \mathrm{~nm}$ with total $\mathrm{EH}^{+}$concentration at $\mathrm{pH}$. The line presents the result of the nonlinear least-squares fit. Inset shows the calculated spectra for monomer (thin line) and dimer (thick line). 
maximum at $301 \mathrm{~nm}$ shifts to $295 \mathrm{~nm}$ and exhibits hypochromicity, whereas the batochromic displacement in the long-wavelength domain is accompanied by intensity diminution when $\left[\mathrm{EH}^{+}\right]_{\mathrm{T}}$ is raised. These marked spectral changes suggest solute association. The concentration dependence of $\varepsilon$ was analysed assuming dimerization without formation of larger aggregates. The fraction $(\alpha)$ of $\left[\mathrm{EH}^{+}\right]_{\mathrm{T}}$ present as monomer is given by the following relationship:

$$
\alpha=\frac{-1+\sqrt{1+8 K_{D}\left[E H^{+}\right]_{T}}}{4 K_{D}\left[E H^{+}\right]_{T}}
$$

where $\mathrm{K}_{\mathrm{D}}=\left[\left(\mathrm{EH}^{+}\right)_{2}\right] /\left[\mathrm{EH}^{+}\right]^{2}$ is the equilibrium constant of dimer $\left(\mathrm{EH}^{+}\right)_{2}$ formation. The measured apparent molar absorption coefficient $(\varepsilon)$ is related to the molar absorption coefficients for the monomer $\left(\varepsilon_{\mathrm{M}}\right)$ and dimer $\left(\varepsilon_{\mathrm{D}}\right)$ as follows

$$
\varepsilon=\varepsilon_{M} \alpha+\varepsilon_{D}(1-\alpha) / 2
$$

The global analysis of the concentration dependence of the absorption spectra using eqs 1 and 2 provided $\mathrm{K}_{\mathrm{D}}=(1.5 \pm 0.2) \times 10^{4} \mathrm{M}^{-1}$, and the spectra displayed as an inset in Figure 1B. The molar absorption coefficients at $301 \mathrm{~nm}$ were $\varepsilon_{\mathrm{M}}=66300 \pm 1000 \mathrm{M}^{-1} \mathrm{~cm}^{-1}$ and $\varepsilon_{\mathrm{D}}=38600 \pm$ $2000 \mathrm{M}^{-1} \mathrm{~cm}^{-1}$ for the monomer and dimer, respectively. The excellent match between the measured and computed data implies that only two $\mathrm{EH}^{+}$ions are associated, negligible amount of larger aggregates is produced in the $0<\left[\mathrm{EH}^{+}\right]_{\mathrm{T}} \leq 230 \mu \mathrm{M}$ concentration range.

\subsection{Thermodynamics of dimerization}

To determine the thermodynamic parameters of association, isothermal calorimetric titrations (ITC) were performed at $298 \mathrm{~K}$. About $81 \%$ of the solute is dimerized in $747 \mu \mathrm{M} \mathrm{EH}^{+}$solution. When such a concentrated solution was gradually added to water keeping $\mathrm{pH} 4$ constant, the enthalpograms displayed in Figure 2 were obtained. Substantial heat is absorbed after each 

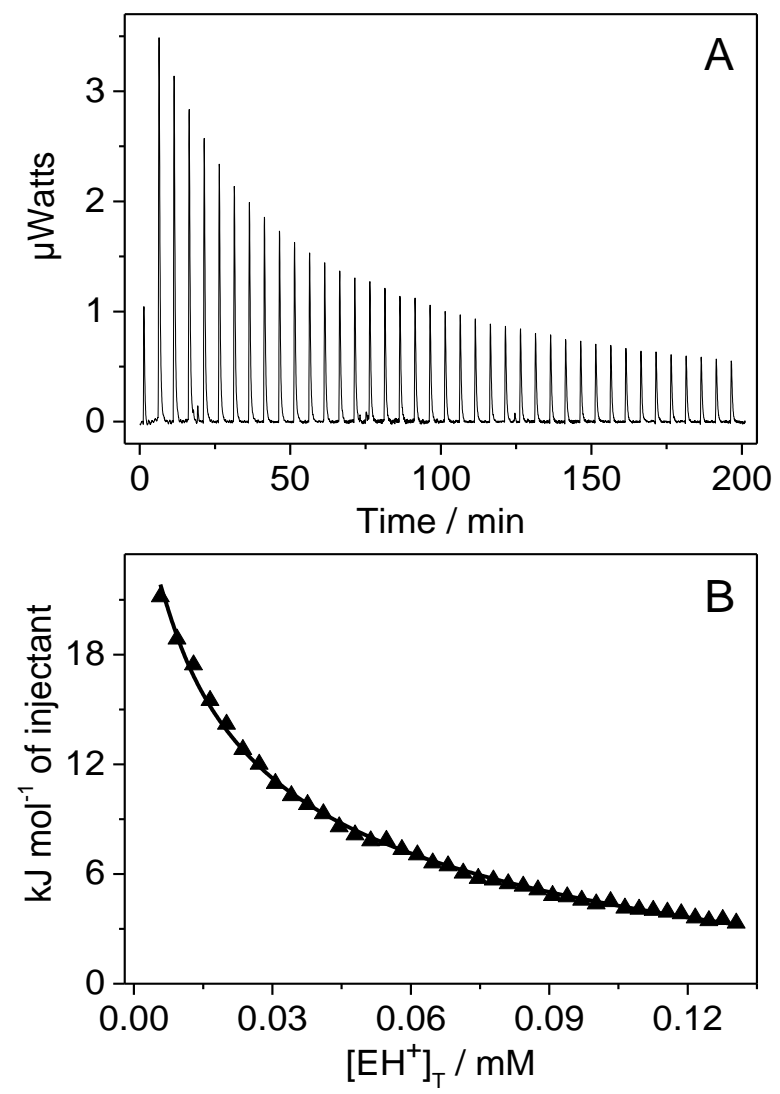

Figure 2. (A) Heat uptake upon addition of $747 \mu \mathrm{M} \mathrm{EH}^{+}$solution into water in increments of 7 $\mu \mathrm{l}$ at $\mathrm{pH}$ 4. (B) Integrated heat absorbed after injection as a function of total $\mathrm{EH}^{+}$concentration. The line represents the fitted function.

addition indicating that the dimer dissociation is an endothermic process. As the amount of $\mathrm{EH}^{+}$ grows in the calorimeter cell, the extent of $\left(\mathrm{EH}^{+}\right)_{2}$ dissociation progressively diminishes after successive injections leading to the lessening of the absorbed heat. The dependence of the integrated heat signals on the total alkaloid concentration was analysed on the basis of the simple $2 \mathrm{EH}^{+} \rightleftharpoons\left(\mathrm{EH}^{+}\right)_{2}$ equilibrium using the association constant $\left(\mathrm{K}_{\mathrm{D}}\right)$ and the enthalpy change $\left(\Delta \mathrm{H}_{\mathrm{D}}\right)$ of dimerization as fitting parameters. From these quantities, standard free energy $\left(\Delta \mathrm{G}_{\mathrm{D}}\right)$ and entropy changes $\left(\Delta \mathrm{S}_{\mathrm{D}}\right)$ of $\left(\mathrm{EH}^{+}\right)_{2}$ formation were calculated using the equation 


$$
\Delta \mathrm{G}_{\mathrm{D}}=-\mathrm{RT} \ln \mathrm{K}_{\mathrm{D}}=\Delta \mathrm{H}_{\mathrm{D}}-\mathrm{T} \Delta \mathrm{S}_{\mathrm{D}}
$$

where $\mathrm{R}$ denotes the gas constant and the temperature is $\mathrm{T}=298 \mathrm{~K}$. The derived binding parameters are summarized in Table 1.

Table 1 Association constants and thermodynamic parameters for $\mathrm{EH}^{+}$dimerization at $298 \mathrm{~K}$ in $10^{-4} \mathrm{M} \mathrm{HCl}$ aqueous solution

\begin{tabular}{|c|c|c|c|c|c|}
\hline \multicolumn{2}{|c|}{$\mathrm{K}_{\mathrm{D}} / 10^{4} \mathrm{M}^{-1}$} & $\Delta \mathrm{G}_{\mathrm{D}} / \mathrm{kJ} \mathrm{mol}^{-1}$ & $\Delta \mathrm{H}_{\mathrm{D}} / \mathrm{kJ} \mathrm{mol}^{-1}$ & $\mathrm{~T} \Delta \mathrm{S}_{\mathrm{D}} / \mathrm{kJ} \mathrm{mol}^{-1}$ & $\Delta \mathrm{S}_{\mathrm{D}} / \mathrm{J} \mathrm{mol}^{-1} \mathrm{~K}^{-1}$ \\
\cline { 1 - 5 } ITC & absorption & & & & \\
\hline $1.3 \pm 0.1$ & $1.5 \pm 0.2$ & $-23.5 \pm 0.5$ & $-60 \pm 2$ & $-37 \pm 2.5$ & $-124 \pm 9$ \\
\hline
\end{tabular}

An excellent agreement was obtained between the $\mathrm{K}_{\mathrm{D}}$ values determined by calorimetric and spectrophotometric methods. The thermodynamic data show that dimerization is an enthalpycontrolled process. The substantial negative $\Delta \mathrm{H}_{\mathrm{D}}$ suggests that the $\pi-\pi$ interaction between the aromatic rings of two $\mathrm{EH}^{+}$and the changes in the hydrate shell result in a significant enthalpy gain. The predominant enthalpic contribution to the driving force is partly reduced by the unfavourable entropic term due to the diminution in the number of degrees of freedom upon the interaction between $\mathrm{EH}^{+}$ions and the change of the water structure around the solutes. The $\Delta \mathrm{H}_{\mathrm{D}}$ and $\Delta \mathrm{S}_{\mathrm{D}}$ values of $\left(\mathrm{EH}^{+}\right)_{2}$ formation (Table 1) correspond to the trend in the linear enthalpyentropy correlation for the dimerization of various dyes and aromatic compounds [14]. However, self-association rarely occurs for alkaloids. The interaction of the tropolone moieties of colchicine was found to result in weakly-bound dimers [15]. The fully conjugated ring system of coralyne promoted the formation not only of dimers but also of multiple aggregates [16,17]. Spectrophotometric measurements provided $K_{D}=1.1 \times 10^{5} \mathrm{M}^{-1}$ for the equilibrium constant of coralyne dimerization in water $[16,18]$. Due probably to its less extended aromatic structure, $\mathrm{EH}^{+}$ 
had about one order of magnitude smaller $K_{D}$ value (Table 1). Delbarre and co-workers reported stacked n-mer formation of $\mathrm{EH}^{+}$and its 9-substituted derivatives in acetate buffer of $0.055 \mathrm{M}$ ionic strength in $\mathrm{D}_{2} \mathrm{O}$ [19]. The enthalpy change upon stacking was found to be $-65.3 \mathrm{~kJ} \mathrm{~mol}^{-1}$, which is close to the $\Delta \mathrm{H}_{\mathrm{D}}=-60 \pm 2 \mathrm{~kJ} \mathrm{~mol}^{-1}$ value obtained for dimerization in the present work.

On the basis of the ${ }^{1} \mathrm{H}$ NMR spectra, self-assembly of the planar molecules in inverted geometry was proposed. Such a geometry was also found in 9-hydroxyellipticinium acetate crystals by Xray diffraction method [19]. In accordance with the experimental data, Figure S1 in Supplementary Information shows the probable structure of $\left(\mathrm{EH}^{+}\right)_{2}$ dimer obtained by DFT calculations. The constituents have planar geometry and anti-parallel orientations allowing $\pi-\pi$ interactions between the benzene rings of the two $\mathrm{EH}^{+}$molecules. Since no dimerization is observed in organic solvents [3], hydrophobic interaction may play essential role in $\left(\mathrm{EH}^{+}\right)_{2}$ formation. The changes in the structure of the hydrate shells and the redistribution of the water network around the solutes significantly contribute to the driving force of dimerization also in the case of other compounds [14].

\subsection{Effect of dimerization on the fluorescence characteristics}

The results of fluorescence spectroscopic measurements confirmed dimerization. The fluorescence maximum shifted about $6 \mathrm{~nm}$ towards longer wavelength upon increase of the $\mathrm{EH}^{+}$ concentration from 0.6 to $77 \mu \mathrm{M}$, and a concomitant marked alteration of the fluorescence decays was observed (Figure 3A). The fluorescence intensity $(I(t))$ versus time $(t)$ traces could be described well with a biexponential function

$$
I(t)=a_{M} \exp \left(-\frac{t}{\tau_{M}}\right)+a_{D} \exp \left(-\frac{t}{\tau_{D}}\right)
$$


In dilute solution, the monomer emission of $\tau_{\mathrm{M}}=2.0 \pm 0.1 \mathrm{~ns}$ lifetime prevailed, but another component of $\tau_{\mathrm{D}}=7.5 \pm 0.3 \mathrm{~ns}$ lifetime appeared at higher concentrations due to dimer formation (Table 2). Both lifetimes were constant within the limits of experimental errors indicating that higher aggregates were not produced. The amplitude of the longer-lived emission $\left(\mathrm{a}_{\mathrm{D}}\right)$ grew with $\mathrm{EH}^{+}$concentration at the expense of the amplitude of the monomer fluorescence $\left(\mathrm{a}_{\mathrm{M}}\right)$. The ratio of the dimer and monomer fluorescence intensity $\left(I_{D} / I_{M}\right)$ at the monitoring wavelength $\left(\lambda_{\mathrm{F}}=530 \mathrm{~nm}\right)$ is given as follows:

$$
\frac{I_{D}}{I_{M}}=\frac{a_{D} \tau_{D}}{a_{M} \tau_{M}}=\frac{f_{D}\left(1-10^{-\varepsilon_{D} l(1-\alpha)\left[E H^{+}\right]_{T} / 2}\right)}{f_{M}\left(1-10^{-\varepsilon_{M} l \alpha\left[E H^{+}\right]_{T}}\right)}
$$
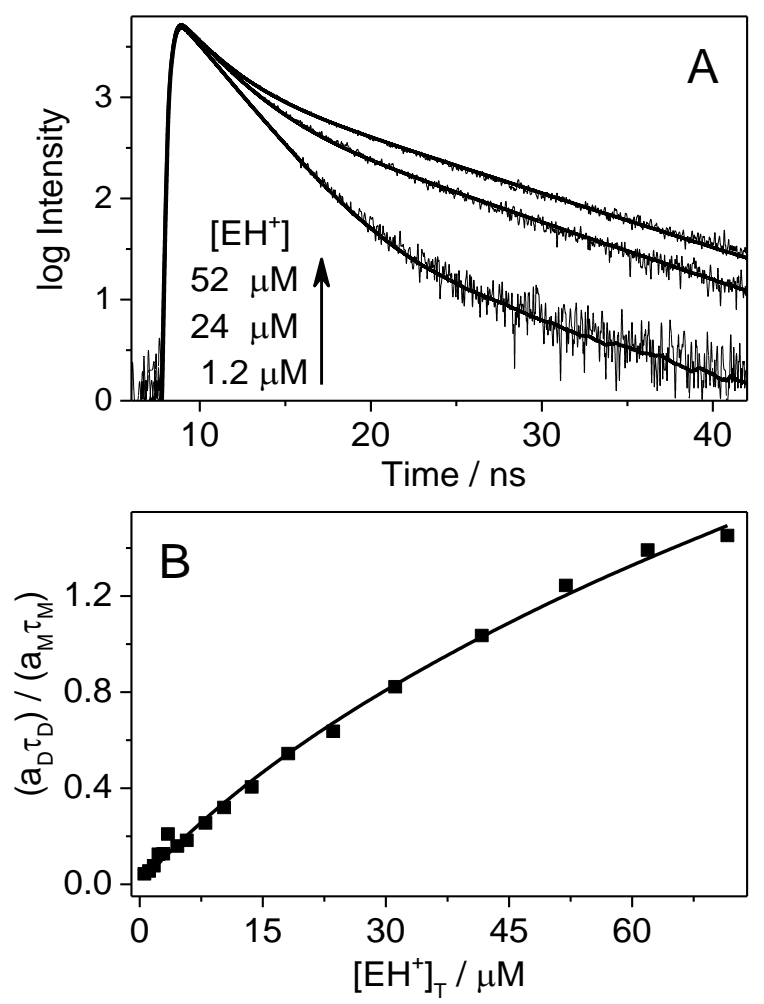

Figure 3. (A) Logarithm of fluorescence intensity at $530 \mathrm{~nm}$ vs time profiles at 52,24 and 1.2 $\mu \mathrm{M}\left[\mathrm{EH}^{+}\right]_{\mathrm{T}}$ in $10^{-4} \mathrm{M} \mathrm{HCl}$ aqueous solution. (B) Ratio of the amplitude and fluorescence lifetime products for the dimer and monomer emissions as a function of total $\mathrm{EH}^{+}$concentration. 
Table 2 Concentration dependence of the fluorescence lifetimes and their amplitudes in $\mathrm{EH}^{+}$ aqueous solution at $\mathrm{pH} 4$

\begin{tabular}{|c|c|c|c|c|c|}
\hline$\left[\mathrm{EH}^{+}\right] / \mu \mathrm{M}$ & $\tau_{\mathrm{M}} / \mathrm{ns}$ & $\tau_{\mathrm{D}} / \mathrm{ns}$ & $\mathrm{a}_{\mathrm{M}}(\%)$ & $\mathrm{a}_{\mathrm{D}}(\%)$ & $\chi^{2}$ \\
\hline 1.16 & 2.1 & 7.5 & 98.5 & 1.5 & 1.17 \\
\hline 4.61 & 2.1 & 7.5 & 95.7 & 4.3 & 1.03 \\
\hline 10.3 & 2.1 & 7.5 & 91.8 & 8.2 & 1.18 \\
\hline 18.1 & 2.0 & 7.4 & 87.0 & 13.0 & 1.08 \\
\hline 31.1 & 1.9 & 7.3 & 80.7 & 19.3 & 1.13 \\
\hline 61.9 & 1.9 & 7.6 & 75.1 & 24.9 & 1.25 \\
\hline
\end{tabular}

where $f_{\mathrm{D}} / f_{\mathrm{M}}$ denotes the relative fluorescence efficiency at $\lambda_{\mathrm{F}}$ and $l=1 \mathrm{~cm}$ is the optical path. The rise of $\left(\mathrm{a}_{\mathrm{D}} \tau_{\mathrm{D}}\right) /\left(\mathrm{a}_{\mathrm{M}} \tau_{\mathrm{M}}\right)$ ratio with $\mathrm{EH}^{+}$concentration (Figure $3 \mathrm{~B}$ ) was fitted by eq 5 . The $\alpha, \varepsilon_{\mathrm{M}}$ and $\varepsilon_{\mathrm{D}}$ values were taken from the results of spectrophotometric titrations (vide supra). The calculated function matched the experimental data and $f_{\mathrm{D}} / f_{\mathrm{M}}=2.1$ was obtained at $530 \mathrm{~nm}$ indicating that the dimer emits more efficiently than the monomer at this wavelength. The excellent fit of the time-resolved fluorescence data with eq 5 proves that the diminution of the monomer fraction $(\alpha)$ due to dimerization results in the growth of the amplitude of the longlived fluorescence component. In basic solution, dimerization cannot be examined due to the low solubility of E. At neutral $\mathrm{pH}$, E concentration of only $\sim 0.62 \times 10^{-6} \mathrm{M}$ was reached $[5,20]$. Significant lengthening of the fluorescence lifetime has also been observed upon dimerization of other compounds. For example, dimerization brought about 20-fold deceleration of the deactivation from the singlet-excited state for oxacarbocyanines [21], whereas almost 9-fold slowing down was found for a merocyanine dye [22]. The coralyne monomer and dimer had 9.7 and 40.7 ns fluorescence decay times, respectively [18]. 


\section{Conclusions}

The double-exponential decay kinetics of $\mathrm{EH}^{+}$is due to the coexistence of monomer and dimer in aqueous solution at $\mathrm{pH} 4$ and the longer-lived fluorescence component of $7.5 \mathrm{~ns}$ lifetime arises from $\left(\mathrm{EH}^{+}\right)_{2}$ emission. This knowledge is inevitably necessary for the correct interpretation of the fluorescence decays of $\mathrm{EH}^{+}$in the presence of all types of additives. Dimerization may significantly influence the biological activity, binding characteristics, and photoinitiated processes of $\mathrm{EH}^{+}$. Taking into account dimer formation is essential because otherwise a systematic error appears in the spectrophotometrically measured $\mathrm{EH}^{+}$concentrations and in all quantities derived therefrom. The association of two $\mathrm{EH}^{+}$probably plays an important role also under physiological conditions because the high ionic strength diminishes the electrostatic repulsion between the charged monomers promoting thereby the interaction between alkaloid cations. The local concentration of $\mathrm{EH}^{+}$and the polarity of the microenvironment can permit dimerization in the various parts of biological systems.

\section{Acknowledgement}

The authors very much appreciate the support of this work by the Hungarian Scientific Research Fund (OTKA, Grant K104201). Z. M. thanks the support of the János Bolyai Research Scholarship of the Hungarian Academy of Sciences.

\section{References}

[1] S. Pandrangi, R. Chikati, P. Chauhan, C. Kumar, A. Banarji, S. Saxena, Tumor Biol., 35 (2014) 723-737.

[2] A.M. Pohlit, L.F. Rocha e Silva, M.C. Henrique, A. Montoia, R.C.N. Amorim, S.M. Nunomura, V.F. Andrade-Neto, Phytomedicine, 19 (2012) 1049. 
[3] S.Y. Fung, J. Duhamel, P. Chen, J. Phys. Chem. A, 110 (2006) 11446-11454.

[4] S.Y. Fung, H. Yang, P. Chen, Plos One, 3 (2008) e1956.

[5] S.Y. Fung, H. Yang, P.T. Bhola, P. Sadatmousavi, E. Muzar, M. Liu, P. Chen, Adv. Funct. Mater., 19 (2009) 74-83.

[6] B.L. Sailer, J.G. Valdez, J.A. Steinkamp, Z. Darzynkiewicz, H.A. Crissman, Experimental Cell Research, 236 (1997) 259-267.

[7] M.A. Schwaller, F. Sureau, P.Y. Turpin, J. Aubard, J. Luminesc., 48-49, Part 1 (1991) 419424.

[8] M.A. Schwaller, B. Allard, F. Sureau, F. Moreau, J. Phys. Chem., 98 (1994) 4209-4211.

[9] S.J. Froelich-Ammon, M.W. Patchan, N. Osheroff, R.B. Thompson, J. Biol. Chem., 270 (1995) 14998-15004.

[10] K. Gavvala, A. Sengupta, R.K. Koninti, P. Hazra, J. Phys. Chem. B, 117 (2013) 1409914107.

[11] K. Gavvala, R.K. Koninti, A. Sengupta, P. Hazra, Phys. Chem. Chem. Phys., 16 (2014) 14953-14960.

[12] M. Megyesi, L. Biczók, J. Phys. Chem. B, 114 (2010) 2814-2819.

[13] G. Dodin, M.-A. Schwaller, J. Aubard, C. Paoletti, Eur. J. Biochem., 176 (1988) 371-376.

[14] K. Murakami, Dyes Pigments, 53 (2002) 31-43.

[15] Y. Engelborghs, J. Biol. Chem., 256 (1981) 3276-3278.

[16] A.N. Gough, R.L. Jones, W.D. Wilson, J. Med. Chem., 22 (1979) 1551-1554.

[17] B. García, S. Ibeas, R. Ruiz, J.M. Leal, T. Biver, A. Boggioni, F. Secco, M. Venturini, J. Phys. Chem. B, 113 (2008) 188-196.

[18] M. Megyesi, L. Biczók, H. Görner, Photochem. Photobiol. Sci., 8 (2009) 556-561. 
[19] A. Delbarre, B.P. Roques, J.B. Le Pecq, J.Y. Lallemand, X. Nguyen Dat, Biophys. Chem., 4 (1976) 275-279.

[20] J. Liu, Y. Xiao, C. Allen, J. Pharm. Sci., 93 (2004) 132-143.

[21] M. Caselli, L. Latterini, G. Ponterini, Phys. Chem. Chem. Phys., 6 (2004) 3857-3863.

[22] U. Rösch, S. Yao, R. Wortmann, F. Würthner, Angew. Chem. Int. Ed., 45 (2006) 7026-7030. 